\title{
Practice and Challenges Facing Practical Work Implementation in Natural Science Subjects at Secondary Schools
}

\author{
Abebe Adugna Chala \\ Madda Walabu University, College of Natural Science, Department of Physics \\ Bale-Robe, Ethiopia; P. Box: 247
}

\begin{abstract}
Practical work is very crucial for teaching and learning process in school science and good quality of practical work implementation helps to develop pupils' understanding of scientific processes and concepts. However, it has been shown that practical work in science subjects almost ignored or not effectively implemented in secondary schools in many countries of the world because of different factors. The main purpose of this article was to identify challenges facing implementing practical work in natural science subjects and its practice at secondary schools in different areas of the world based on different published works. The most recent and majorly the last 15 years that published in reputable journals have been critical reviewed and used as a direct source. Hence, the dominant factors frequently that indicated in most findings special in developing countries to implement practical activities of natural science subjects in secondary schools are problems related to school resource are: lab equipment and supply, laboratory manuals, laboratory rooms, class size and ICT access. The second ranked determinant is problem related to teachers and technicians related issues which include: teacher's perception and motivation, teachers' skills competence, teachers work experience, the laboratory technicians, job satisfaction and teachers work load. The other factors are exams and assessments, curriculum and educational administrations are identified as different factors. However, each of them affect the implementation of practical work with varies degree from school to school and also among different countries. The factors affecting in developed countries and developing are somewhat different. The implementation process of practical work in science education is still limited in Ethiopian schools and students perform poorly in science subjects.
\end{abstract}

Keywords: Practical Work, Secondary Schools, practice, challenges.

DOI: $10.7176 / \mathrm{JEP} / 10-31-01$

Publication date: November $30^{\text {th }} 2019$

\section{Introduction}

Practical work is defined as learning experiences in which students interact with materials or with secondary sources of data to observe and understand the natural world (Lunette and et al., 2007). As stated by (Ramnarain, 2011) it is Experimental work and scientific investigations (SCORE, 2008) 'practical and investigative activities', and 'laboratory investigations' (Kibirige \&Tsomago, 2013). The broad perspective of 'learning experiences' will be understood to include the wide range of practical skills, thought and processes that constitute doing science as 'what scientists do' (Benner, 2011).

Hence, Practical work is to describe the kind of lesson activity we are interested in. An 'experiment', particularly in philosophy of science is generally taken to mean a planned intervention in the material world to test a prediction derived from a theory or hypothesis. Practical work in science teaching and learning situations that offer learners opportunities to practice the process of investigations (Stoffels, 2005). Similarly, it is indicated that practical work would involve hands-on and minds-on practical learning opportunities where learners practice and develop various process skills including hypothesizing, observation, interpreting, predicting, problem solving, communicating, and drawing and evaluating conclusions Department of Basic Education (DBE, 2011a). Thus one could define practical work as an activity in which concepts taught in the classroom are linked to real practice in the laboratory or the surrounding environment. Practical work in school science means laboratory based experiences (Tsai, 2003). This definition therefore, requires that learners need to have access to laboratory facilities and equipment in order to develop their scientific process skills.

Learning science has benefits for the country's sustained development and is worthy part of the Nation's school curriculum of one country. The Physical Sciences plays an increasingly important role in the lives of all South Africans due to its influence on the scientific and technological development which underpins our country's economic growth and social well-being of our community. The South African legacy has resulted in limited access to scientific knowledge and devaluing of indigenous scientific knowledge in certain sectors of the community due to the poor quality or lack of education (DoE, 2003). The application of Physical Sciences knowledge has a profound impact on world-wide issues and events such as economic, environmental, social, political, ethical and technological (DoE, 2003).

Practical works in secondary schools of Ethiopia are also studied to identify factors hindering its proper implementation. Researches conducted in Ethiopia indicate that secondary students do not receive the practical experiences specified in the official science curriculum (Samuel Bekalo \&Geoff Welford, 2010). About 85.97\% 
of laboratory activities were not done in science education at secondary schools of Ilu Aba Bora zone (Feyera, 2014). In the same way, about $75 \%$ students had not been engage with practical activities while learning Physics (Endalamaw and et al., 2017).

In Ethiopia it is indicated that students beginning from lower grades have serious knowledge deficits in science and mathematics; this signifies that the quality of science education in primary and secondary schools, which is critical foundations for latter educational development, is at crisis. At this point it looks imperative to raise some questions related to the 70:30 professional mix proposed by MoE. It big challenge to place $70 \%$ of preparatory graduates to higher learning institution in science stream of which $40 \%$ technology and $30 \%$ natural science where students have low achievement in science subjects in general and physics in particular (FSS, 2009).

Therefore, the objective of this review is to identify challenging factors and practice on practical work implementation in natural science education at secondary schools. The researcher is extremely interested to review and identify varies dominant factors hinders the implementing of practical work in secondary schools in natural science at various secondary schools. Additional its practice in wider way from different finding will be collected, organized and presented from different research findings in worldwide. Basically this article attempt to provide answers to the following questions: what are the basic determinant factors for the practical work implementation and practice in science education at secondary schools: to how much extent schools have enough resources to do practical activities in natural science education; do teachers use practical activities in teaching science education in secondary school; in what ways do different assessments that are prepared have been considered to include practical work; do secondary school students have interest and motivations in participation of practical activities in science education. How do policies and curriculum designers have considered the implementation and practice of natural science education; what are the roles of educational administrator in implementing practical activities natural science education.

\section{The Purpose and practice of practical work in science education}

The Purposes of laboratory work in science education have been stated in many literatures in different ways. Students' interpretations of the taught models, used to explain theory, can be tested and re-evaluated through such laboratory work, thus, improving students' conceptual understanding work (Hofstein \& Lunetta, 2004; Högström, Ottander, \& Benckert, 2006; Lazarowitz \& Tamir, 1994). According to (Jenkins, 1999) Laboratory work used to motivate and increase students' interest in science relates more to aims of affective character. The skill category involves laboratory work that aims to allow students opportunity to practice, handling special equipment, using standard techniques, comprehension and execution of instructions.

Different authors in science education contend that practical work in science has many purposes. These are motivation for students, the excitement of discovery, consolidation of theory, development of manipulative skills, knowledge of standard techniques, general understanding of data handling, development of other skills which analytic, evaluative, planning, applied mathematically. The role of practical work in science teaching recorded in the literature includes to encourage accurate observation and description, making phenomenon more real, arousing and maintaining interest and promoting a logical and reasoning method of thought stated in Science Community Representing Education (SCORE, 2008). It is also indicated that understanding of how science works: concepts of scientific process, collaborative working, reproducible results, fair testing (Watts, 2013). In Science, learners do practical work to expand their knowledge in an attempt to understand the world around them (Kolucki \& Lemish, 2011). It develops learners' understanding of ideas, theories and models (Millar \& Abrahams, 2008). Research has established that achievement and skills improved when studnts are taught science using practical work (Kerr, 1963; Turpin \& Cage, 2004; Aladejana \& Aderibigbe, 2007; Watts, 2013).

The school science curriculum in most countries has two distinct purposes; the first one is to provide every young person with sufficient understanding of science to participate confidently and effectively in the modern world. Modern society needs some understanding of the nature of scientific knowledge in order to evaluate claims that may affect their everyday decisions and to reach informed views of public policy. Secondly, is to provide the foundations for more advanced study in science in their future life ( Millar, 2004). The research project which was done in Europe from seven countries (Denmark, Germany, Britain, France, Greece, Italy and Spain) showed there were large differences between countries, in terms of how much time was devoted to experiments. However, there were no major variations in how laboratory work was performed (Séré, 2002). According to this study the main purpose of the laboratory work from a teacher's perspective was to better understand the theory and link theory to practice. Many research studies have indicated the aim of laboratory identifies three main categories of aims: cognitive and affective aims and aims concerned with the acquisition of technique and manual skills. Aims categorized as cognitive, address students' development of knowledge and understanding. In this aspect, laboratory work can be used to help students make links between theory and practice.

In general many researchers have confirmed that learning science is enhanced and the understanding level is improved when students are engaged in science laboratory for practical experiments (Hofstein and Lunetta, 2004; Hofstein, 2004; Lunetta et al., 2007). The laboratory has been given a central and distinctive role in science 
education, and science educators have suggested that rich benefits in learning science come as result of using laboratory activities. Hence, Practical work is basic for students to help them to understand and develop their skills in science education.

Attending laboratory sessions is important in learning physical science because practical work in a way brings to life what is explained in textbooks. By seeing educators demonstrating or conducting experiments themselves, learners supplement what is in textbooks and as a result learning is enhanced. An advantage of laboratory usage is that it helps improve learners' higher order learning skills such as analysis, problem solving and evaluating. Secondary school is basic in preparing students for science education. It is at this level they expose, observe and interact with laboratory equipment, activities and learn precaution or safety rules. Poor performance in Physical Sciences is due to absence of Practical work while teaching of Physical Sciences (Makgato, 2007). A secondary schools laboratory should have the equipment necessary to conduct meaningful demonstrations and experiments. However, many research findings in different countries have indicated practical work either totally does not be done or poor implementation in secondary schools in many countries of the world.

The United Kingdom has a very strong emphasis on practical work unlike the majority of other countries (Woolnough, 1998). It has been found that teachers in England are more frequently adopting the hands-on approach to teaching and as a consequent; their students are spending more lesson time on practical work over their international counterparts (Woodley, 2009). Certainly, according to the (House of Commons, 2002a), students in Hong Kong and Thailand are the only countries where students spend more time undertaking practical work than England.

Moreover, in countries such as Greece and Ireland teachers rarely conduct practical work, mainly due to the scarcity of resources. Yet even where resources are abundant, such as in Germany, the routine seems to be more teacher-led practical work than any other approach (Alsop, 1991; Solomon, 1998). Martínez-Losada and GarcíaBarros (2005) found that practical work in Spanish schools was insufficient primarily due to the nature of the culture tending to inhibit any innovation or change. Similar findings in the Trends in International Mathematics and Science Study (TIMSS, 2000) stated that the Czech Republic's intended curriculum had minor or no emphasis on any aspect of practical work along with many other countries having little emphasis in their curricula. There are countries, such as Italy and Greece, which are intending to increase the use of practical work as a pedagogical method (Leach \& Paulsen, 1999; Wellington, 2005).

The main factors frequently indicated for the failure of implementation include: Large class size and lack of resources, lack of laboratories and lab equipment; lack of laboratory technicians; and large classes (Mokotedi, 2013). Similarly, studies that have been done in South African schools have shown that some teachers do not use practical work to teach physical sciences (Rumnarain, 2011; Hatting \& Rogan, 2007). Further conditions inhibiting the use of practical work when teaching Physical Sciences are some teachers teach subjects in which they are not specialized (Muwanga-Zake, 2008, Onwu \& Stoffels, 2005). Teachers who teach subjects which they do not specialize are known to be reluctant to do practical work (SCORE, 2008; Soares\& Lock, 2007; Abrahams \& Millar, 2008). Muwanga-Zake (2008) observed that many rural schools in South Africa do not have laboratories and it is reasonable to conclude that such schools also did not have technicians. Others studies also point to learners' persistent lack of experimentation skills (Onwu\&Stoffels, 2005; Mji\&Magkato, 2006; Luben et.al., 2010; Ramanrain, 2014). Sometimes high school graduates are hired to work as untrained laboratory technicians from the same practical-work-starved or deficient school system and hence cannot effectively function as laboratory technicians (Smithers \& Robinson, 2005) and (Helliar \& Harrison, 2011).

Consequently, in the absence or poor implementation of practical work learners' performance in science subjects would be poor and lose interest. The other finding that has important implications is that the doing of practical work is significantly dependent on teachers' motivation. Those who are motivated to do practical work will find ways to do so even in the most poorly resourced of schools. Conversely those who are not motivated will not do practical work even when they have access to the best of resources. Only when the teachers are ready, willing and able to use resources they implement (Hattingh, 2007). In the case study conducted by (Rogan \& Aldous, 2005) no relationship was found between the availability of resources and the level of practical work performed. This finding suggests that improving the resources will make little difference unless accompanied by other interventions as well.

Hence, basic determinant factors for the practical work implementation and practice in science education at secondary schools have been identified in this review. The summery of factors are presented in the following table 1 , with each basic factor again sub factors under them. It is illustrated with rank order based on the most frequently stated in different literature. Moreover, the detail description of each factors are presented in the next sections. 
Table 1: challenging factors to practical work in science.

\begin{tabular}{|c|c|c|}
\hline rank & basic factors & $\begin{array}{l}\text { detail list of factors under each basic factors in rank } \\
\text { order }\end{array}$ \\
\hline 1 & Facility and resource related issues & $\begin{array}{l}\text { 1. Lab equipment and supply } \\
\text { 2. Laboratory manuals } \\
\text { 3. Laboratory room } \\
\text { 4. Large class size allocation } \\
\text { 5. The role of ICT }\end{array}$ \\
\hline 2 & $\begin{array}{l}\text { Teachers and laboratory technicians } \\
\text { related issues }\end{array}$ & $\begin{array}{l}\text { 1.Teacher's perception and motivation } \\
\text { 2. Teachers skills competence } \\
\text { 3. Teachers work experience } \\
\text { 4. The need for technicians } \\
\text { 5. Job Satisfaction } \\
\text { 6. Teachers work load } \\
\text { 7. Class time }\end{array}$ \\
\hline 3 & Exam and Assessment related issues & Class room and standard examinations \\
\hline 4 & Students related issues & Student's motivation and perception \\
\hline 5 & Curriculum related issues & content of the curriculum \\
\hline 6 & $\begin{array}{l}\text { Educational administrations related } \\
\text { issues }\end{array}$ & $\begin{array}{l}\text { 1. School principals } \\
\text { 2. Higher authorities } \\
\text { 3. Support and recognition from other stakeholders }\end{array}$ \\
\hline
\end{tabular}

\section{The role Facility and resource related issues in affecting the implementing practical work in science} education

Equipment and facilities related issues are very significant constraints for the implementation of practical work and indicated in different findings. Having the right resources available at the appropriate time is an obvious prerequisite for practical work implementation.

\subsection{Laboratory equipment and supply}

For all kinds of scientific experiments, whether in a research laboratory in schools or colleges, there is the need for various laboratory apparatus and laboratory equipment. Laboratory apparatus are tools and equipment used by scientists, researchers and students to perform their tasks. The laboratory apparatus differ from laboratory to laboratory, from subject to subject. The apparatus and equipment found in any given laboratory could vary depending on the field of study, nature of study and level of the researchers, like high school, or professional. The various fields of science are complex and very wide.

There are certain general purpose laboratory apparatus, which are just a few of laboratory apparatus used by scientists today. For instance, as stated by (Ciroma and Bakori, 2010) asserted that working in science laboratory can only be possible if there are sufficient pieces of equipment for experiment. Laboratory equipment are the key to any practical work, which promotes long term memory in students, enhances pupils development of the ethical dimension of science, inspires the spirit of collaboration and active participation among learners, exposes learners to scientific experiences that could ultimately help them in developing scientific attitudes and skills and inculcate in the students the spirit of inquiry and scientific mode of thinking.

According to Shaibu and Mari (2000), laboratory activities stimulate the acquisition of both manipulative and cognitive skills by learners. They observed that laboratory activities in most schools, do not allow learners to carry out investigation that involve designing, experiments, making observation, collecting and interpreting data, to think and evolve solution to problem. Others research evidence also support the view that when science is taught through the medium of practical work, a lot of enjoyable learning took place (Bajah, 1984). Recall of information has been found to be easier when the information to be recalled had initially been presented through a practical approach. Ughamadu (1992) stated that creative use of equipment in teaching science increases the probability that students will learn and improve their performance that they are to develop. Abimbade (1999) showed that instructional or laboratory materials when appropriately used, enhance learning, improve the competence of teachers and make learning more meaningful to learners. Jatau (2008) reported that when instructional equipment are appropriately utilized, they bring about more effectiveness in teaching and learning process, but this depends on teachers ability to use them efficiently. Hence, from its definition and purpose requires that learners need to have access to laboratory facilities and equipment in order to develop their scientific process skills.

But the practice in many African countries has been observed there are problem regarding availabilities of lab equipment and on its usage. For instance, most secondary schools in Nigeria have no science laboratories and the few that have them are at low level equipped and poorly maintained (Ajayi 2008). In effect, this situation of the laboratories is inadequate with the recommended standard by the Federal Inspectorate division of the Federal 
Ministry Education of the country (2002) that each science subject must have a separate well equipped laboratory. The failure of learners to excel in practical examinations was because of "the lack of basic skills for doing simple experiments in the sciences (Ajaja, 2009). The basic reason identified was lack of practical work in teaching science is due to the inability to provide well-equipped science laboratories. Similarly, the reports of (Makgato, 2007) found that the majority of schools in the sample did have poor resources for laboratory work. Again, more than seventy percent of the sampled schools had insufficient laboratory equipment, apparatus and chemicals (Kapting'ei and Kimeli, 2014).

The availability of physical resources on the level of practical work was often claimed by teachers that their ability to do practical work is hampered by the lack of laboratories and science equipment (Hattingh, 2007). Again in the same way other research result also confirm in Nigeria as identified factors lack of equipment in the laboratory have influenced the students' attitude towards practical physics in secondary schools (Adedayo, 2015). In South Africa also schools were found to lack equipment and laboratories (Onwu \& Stoffels, 2005; Mokotedi, 2013; Kibirige and et al., 2014) as well as laboratory technicians to support teachers. In Kenya research conducted shows factors impacted on the successful implementation of effective science teaching was noted that in many secondary schools, science laboratories and equipment are inadequate and the curriculum materials are in short supply (Oyoo, 2013). According to the study by Swain and et al., (1999) teachers in Egypt infrequently carried out practical work primarily, due to lack of resources and equipment.

In opposite some finding justify the availability of resource and implementations of practical work do not have significant relationship. In some well-resourced schools teachers do very few science demonstrations and almost no classroom experiments which results in learners not attaining the skills necessary for learning science. For example, the case studies done by Rogan \& Aldous (2005), where again no relationship was found between the availability of resources and the level of practical work performed. On this case study school had four laboratories, but did zero practical work implementation. The finding identified that improving the resources would make little difference unless accompanied by other interventions as well. Similarly, In Kabul Laboratory materials and equipment have been distributed in most of the schools. Again, the survey research showed that most of the schools have a laboratory and a lab technician, however, a high percentage of the teachers believed that the material and equipment is not enough for teaching and materials are not to the standard and not adopted for teaching (Farzana, 2014).

Also Hattingh (2007) have argued that there is no correlation between resources and practical work, this study has reported otherwise, and argues instead that improving resources will make some difference when accompanied by other interventions as well. These interventions include the motivation of teachers, training of teachers (Ajaja, 2009) and training of how to use equipment supplied to schools (MuwangaZake, 1998). Teachers who are motivated to do practical work will find ways to do so even in the most poorly resourced schools (Hattingh, 2007). Similarly in most schools of Ethiopia lack resources that are required for implementing practical work. In some of the older schools a considerable number of equipment and chemicals were present; however these have been kept idle for years without usage and consequently most of the equipment were broken and parts missing (Gebrekidan, 2014).

In Ethiopia science teachers do not usually find it convenient to make laboratory work the center of their instruction. They usually complain of lack of materials and equipment to carry out practical work. At the same time, it is possible that some of these materials and equipment may be locked up in the school laboratory store without teachers being aware of their existence (Endalamaw and et al., 2017). There are no well-prepared laboratories Chemicals, apparatus and laboratory room haven given less function for the fact that the chemicals on the laboratory are highly expired and outdated, and dangerous for the students as well as for the laboratory technicians (Feyera, 2014). In Southern Ethiopia at Secondary and Preparatory Schools it was confirmed that about $78.03 \%$ students responded that physics class room teacher never used laboratory for practical work to teach Physics (Solomon and Kedir 2015). The main reason indicated in the finding was the lack of interest of physic teachers and lack of equipment in the laboratory. Similarly, study conducted in Bale Southeast Ethiopia indicated about $89 \%$ the teachers respondents are not implementing practical work because lack of laboratories and equipment (Abebe and et.al 2019a). In general in most schools in Ethiopia no practical work is implemented due to lack of equipment and other laboratory facilities. But in some schools because of lack of motivation of teachers and support of school principals practical work implementation hindered and have made negative impact on students' academic achievement in science education.

\subsection{Laboratory manuals}

School teachers in the most commonly used laboratory style the instructor explains the topic which is going to be investigated and link it with previous work, then the students just repeat the steps by imitating the teacher or follow the laboratory manual (Tamir, 1977). This style used by the teachers is widely the cook book approaches as all the teachers prefer the clear and predetermined outcome for their laboratory outcome and they do not ask the students to create the procedure and instead they use a prescribed manual. The advantage of this style was to 
provide the opportunity for a large number of students to perform the same activity and saving resources such as time, instructors, place equipment and materials (Lagowyski, 1990).

In Kenya factors impacted on the successful implementation of effective science teaching was noted that in many secondary schools the curriculum materials like laboratory manuals are in short supply (Oyoo, 2013). In case of Ethiopian secondary schools do not have practical guide or laboratory manuals for science education. Effectiveness in Physics laboratory instruction requires that learners be provided with practical guides. These resource give a wide range of practical activities together with detailed procedures to be followed in which as a consequence boost practical instruction. To practice laboratory experiments, there are no well-prepared laboratory manuals (Feyera, 2014). Similarly in Nigeria as one of Laboratory-related factors the lack instructional materials like laboratory guidance and too short period allocated for practical work was the problems identified for implementation of practical work (Adedayo, 2015). As a result it is the determinant factor to practice practical work, which makes negative impact on students' academic achievement in science education. According to the finding in (Makgato, 2007) also indicated that lack of practical experiments in sample schools contributed to the poor performance of learners in Physical Sciences Schools that did not conduct experiments highlighted the lack of resources like laboratory manual in schools. All the schools of the study sample do not have lab manuals for each subject (Physics, chemistry, biology) to implement practical work. As a result $83 \%$ of the secondary schools in the area are challenged to implement practical work (Abebe and et.al. 2019b). Hence, laboratory manuals are the key determinants for the implementation of practical work in secondary schools in natural science education.

\subsection{Laboratory room}

Laboratories have multiple benefits ranging from making learning concrete to lying basis for science education in the subsequent levels (Hunde \& Tegegne, 2010). There is no controversy that science teaching must take place in a laboratory. Science simply belongs there as naturally as cooking belongs in a kitchen and gardening in a garden. Books gardening manuals can be read anywhere, but the smells, taste, labour and atmosphere can only be evoked in those who already know the reality (Solomon, 1994). In laboratories a minimum requirement room should have enough space; should have gas electricity and water in sufficient quantity to use; be 'future proofed' as far as possible (SCORE , 2008)

In most African countries single science laboratory room serve for all the sciences education. In such cases the time allocated for each science subject cannot sufficiently provide for the day to day practical activities. The single science laboratory system was better suited to the already phased out secondary school curriculum that incorporated Physical and Biological sciences (Kapting'ei and Kimeli, 2014). The outcome study made by Adedayo (2015) revealed that the possible laboratory-related factors influencing the students' attitude towards practical physics in secondary schools in Ekiti state were lack of separate physics laboratory. Laboratory room is not proportional with the number of students and some schools do not have totally laboratory rooms, materials and technicians (Feyera 2014). Except one all schools of the study sample do not have separate lab room for each science subject (Physics, chemistry, biology) to work properly (Abebe and et.al 2019b).

Also in northern part of Ethiopia the eight governmental schools in Mekelle city in the Tigray region have been indicated that science laboratories were at a very poor status. Most of the laboratory rooms were not to the standard (or not built for laboratory purpose) and lacked even the most basic facilities like running water, source of electricity; working tables, sinks, hoods, etc.. In some cases the rooms had broken windows, roofs, doors etc., and as a result were not secure places in which to keep materials (Gebrekidan, 2014). In most laboratory rooms available in secondary schools of Mekele town were not built for laboratory purpose and lacked even the most basic facilities like running water, source of electricity; working tables, sinks, hoods (Tesfamariam \& et al, 2014). This shared truth with the survey that was done in Afar which the laboratory rooms of available were common laboratories for science were too small to hold all students and not suitable to work in, due to lack of ventilation as far as the temperature of the environment is very hot (Tolessa and Mohammed, 2016). In some schools even the rooms are not built for laboratory purpose, doors, windows, roofs are broken. Totally the laboratory rooms and laboratory environments are dirty and not suitable to work in.

\subsection{Large class size allocation}

It is noted by different studies generally uneven allocations are made for the study of science in Ethiopia. Many schools have large class sizes, in some cases as many as eighty students, with few possibilities of meaningful group or individual work and few opportunities for direct contact with teachers (Oli, 2014). Hence, Class sizes are often excessively large, and taught in the poorest conditions by limited number of teachers. Similarly, other finding class size of secondary schools in Wolaita and Dawuro zones was extremely large when compared to the standard set by the MOE of Ethiopia (1995), which are 40 per classroom as reported in (Solomon \& et.al. 2015). It was found that $71.69 \%$ of the sample teachers replied that the average number of students in their school was between 70 and 80. In this regard, the majority of class room teachers could not check up their students exercise, homework and assignment. As result the teaching and learning of physics has been highly affected. Students when it comes to 
practical class and large students' population than the available apparatus during physics practical class were identified as students-related factors influencing the students' attitude towards Practical Physics in secondary schools in (Ekiti state Adedayo, 2015).

\subsection{The role of $\mathrm{ICT}$}

If we look at the obstacles to progress in practical science teaching, it seems possible that information and communication technology (ICT) can contribute to progress. This section will look at some research evidence which supports the use of ICT in enhancing learning through practical work. ICT has the potential to impact on practical science in a number of ways. These include sensors for ease of data collection, computational data analysis tools, computer simulations to present science concepts and the Internet for information, including data, concepts and contexts for science. The evidence in the research report is, broadly speaking, that it has so far promised more than it has delivered (Lunetta et al. 2007). The roles of ICT within practical work in science were explored. The majority of respondents feel it should supplement and not replace hands-on activity. Indeed, this research found a low level of expectation that developments of ICT would improve practical work in science. Simulations were considered to have a role in developing understanding, through presenting ideas clearly and attractively. Those showing dangerous situations and those allowing pupils' inputs were considered particularly valuable. There was a concern that pupils might not be taught that simulations could not provide evidence (SCORE, 2008).

The use of ICT is a vexed question that exposes inherent tensions. There is, however, an underlying consensus that ICT should supplement and enhance practical work not replace it. Plasma television is used in Ethiopia as one of its purpose to replace practical work activities by showing different simulation and experimental work. However, it is not implemented or effectively used due to electric power supply problem and other factors and there is no continuous distribution even in those schools which have plasma television (Tolessa and Mohammed, 2016). In Ethiopian secondary schools there are availabilities of computer center. But the status of their service to help students in learning science education is found at very limited potential. Many of them are not giving service because of lack of maintenance, few numbers and other factors. One of the studies showed that though there was existence of ICT center at schools it was not giving function for the students because it was not proportional to the number of students (Adugna, 2017). The large majorities of schools in the developing world are poorly equipped for hands on science or have no equipment at all. ICT can also compliment by software simulation of practical work where there is shortage of human and material resource.

To sum up, resources in the form of laboratories, equipment and ICT basic services seem to impact on the use of practical work. Generally, Schools that are under resourced tended to do less practical work compared to schools that have adequate resources as evident from this study. Schools that have better resourced and could do better organized practical work than schools that have fewer resources and poorer infrastructure.

\section{Teachers and technicians related issues}

The most prominent factors in teachers' decisions to use practical work depend on the teachers' perceptions of their learners. Teachers who perceive their learners to be motivated and non-disruptive are more likely to engage learners in higher-level types of practical work 2007). The types of practical work that can be done depend on the teacher's perception and motivation (Hatting, 2007). Teachers who are motivated to do practical work will find ways to do so even in the most poorly resourced schools. Also, those who are not motivated will not do practical work even when they have access to the best of resources. The teachers' poor motivation, lack of skills in planning flexible and creative lessons, and lack of understanding of curriculum objectives are all likely to be contributory factors in determining why so much of the science that is taught appears to diverge from the expectations of the curriculum developers (Oli, 2014).

Hence, teachers have to get training on how to use the existing materials and how to implement the activities designed in the curriculum. Some of the research results in Ethiopia indicate secondary schools experienced, in one way or another, unsatisfactory teaching conditions (Oli, 2014). The causes of science teachers' low motivation, the schools were characterized by constraints in relatively low salaries, whose real value has been eroded over time. Similarly, other finding also showed that, teachers' lack of competency in their subject and method of teaching as well as lack of interest and motivation to be engaged in their professional tasks and declining interest of students to learn practical work in Physics (Endalamaw and et al., 2017). Again, in Wollega Zone Preparatory Schools about only $5 \%$ teachers were using laboratories to teach science.

Doing of practical work is not significantly dependent on whether teachers have physical resources (e.g. laboratories, science apparatus or portable laboratory stations). It seems that those who are motivated to do practical work will find ways to do even in the most poorly resourced of schools. Conversely, those who are not motivated will not do practical work even when they have access to the best of resources. At the moment there appears to be no link between the provision of resources and the capacity of teachers. Some studies found that only when the teacher concerned indicated that he or she was ready, willing and able to use resources they implement 
(Hattingh, 2007).

\subsection{Teachers skills competence}

Teachers' skills play a pivotal role in the process of promoting change within their own laboratory, classrooms as well as in schools and education systems generally. The success of practical work in science education in secondary school will depend to a large extent on the teachers' involvement in planning and implementation skills. They manages the entire school, teachers facilitate learning, handle the laboratory implementation and help their students transfer what they have learned theoretical to practical work settings. Qualifications and experience are very important in this regard, but more significantly, the pedagogic style practiced by teachers will need to be childcentred to address practical work in science learning and school-based practices that put the best interest of student at the center of all decision-making processes. Teachers have problems of how to teach and what to teach (Adeboyenga, 2010). So the way the teacher teaches need serious improvement in science education and practical in particular. When students are well taught, they will be able to apply laboratory training in solving their individual and social problems (Henshaw, 2013). The students are not properly taught because have blamed the declining performance of students to lack of hands-on activities (Bello, 2008) and (Igweh, 2013). If one pays a visit to school you would observe one of these three activities taking place rather than practical activities namely-written work, copy note, listening and assignment dominates science classes.

As stated in the finding done by Adedayo (2015) while the teachers are professionally qualified and were unbiased in their teaching, students attitudes towards Practical Physics in secondary schools in Ekiti state are influenced by the teachers' poor knowledge of practical work, non-availability of competent physics teacher, absenteeism of the teacher at practical classes, teacher's method of teaching being too advanced than the students, unfriendly attitude of the teachers with the students and late commencement of teaching practical class. Teachers should use varieties of teaching methods to achieve the desired objectives for quality practical lesson for example; demonstration project, individualized and instruction methods. The teaching must be varied to accommodate students at work instead of theorizing most class periods, encourage hands-on activities, take student out to explore in industries, Let them see and touch the instrument and record steps on industrial preparations of simple equipment and models. The teachers must relate their practical instruction with the commercial and industrial environment rather than only the hypothetical standard/ principles that is too academic. They should record step for the preparations of substance as it is in the industry, so that they will be self-reliance and also fit to render service to the industries.

Because of the primary role that teaching plays in supporting student learning in the classroom, the single most important factor in student achievement is the quality of the teacher in that classroom (Marzano, 2003). As reported in Solomon \& et.al. (2015) the data shows, the majority of $81.13 \%$ physics teachers were not attend physics related professional development activities in forms, workshop, seminar, panel discussion and so on. However, the majority respondent $63.2 \%$ reported that there was a habit of mutual experience sharing and cooperative work among physics teachers in the schools. Similarly, teachers from the interview justified that they lack skill in using available laboratory materials in teaching their students (Endalemaw and et al., 2017). But in some areas where there are adequately furnished laboratories and the teachers are not available to teach, effective learning cannot take place. There is a positive relationship between teacher quality and students performance (Oni, 1995). Comber and Reeve (1975) also submit that teacher qualification was found to be positively and significantly correlated to the student's performance in physics in upper secondary grade.

\subsection{Teachers work experience}

Varies studies results have indicated the work experience influences directly the knowledge and skill of teachers on implementing practical work in science. As a result of experience, teachers will develop confidence which is very important personality for the teachers to be successful to overtake planned activities in practical work. The research has been conducted in UK Over $60 \%$ of both primary and secondary teachers said they were fairly confident. The main reasons given for this were experience (including experience gained e.g. as a scientist, prior to becoming a teacher), knowing the subject and having enthusiasm for it, and having time to practice in school or to attend courses and conferences. Teachers must understand that students with limited strength or mobility can have a full laboratory experience with appropriate accommodation, such as a lab assistant (Tenaw, 2015). Higher institutions in Nigeria charged with the responsibility of training science teachers at all levels, are increasingly turning out teachers without requisite laboratory experience. Otherwise science teachers usually lack the necessary confidence to conduct practical classes with their students (Abimbola, 1996).

\subsection{Teachers' Job Satisfaction}

Teacher performance and attitude, which directly aligns with student learning and achievement, is closely connected to job satisfaction (Ostroff, 1992). Maslow, motivational theorist, created a "hierarchy of needs" in his theory of worker motivation. Initial needs include an adequate salary but pertinent to this study are the needs of a 
supportive group of colleagues (support) and obtaining a feeling of being needed (recognition). After the initial needs of people have been met the higher level needs are working toward excellence and self-actualization. Maslow's work indicates that the higher level needs are esteem, recognition and self-actualization and can be pursued and met once the basics have been achieved (Maslow, 1954). Each of these motivational theorists found that recognition, encouragement and respect as motivational factors in improving productivity and self-efficacy. Another aspect of the data analysis in this study is designed to investigate the connection between the demographics of the participants and their need for recognition and support as a key factor in their performance influences.

Hence, teachers who are dissatisfied within the profession are not likely to produce quality lessons and deliver engaging instruction in the classroom (Baker \& Smith, 1997). Teachers that are satisfied with their jobs tend to produce more in the classroom and yield better instructional results with their students. (Baker \& Smith, 1997). Teacher turnover is an expensive problem that might be avoided to a greater extent with more focused and mindful induction and retention programs in place that cater to the needs of the teachers in that area (Darling-Hammond, 2001). Hence, job satisfaction of science teachers can have direct relationship with teaching science and also can affect the implementation of practical work in different secondary schools. But they are a number of determinants for job satisfaction.

\subsection{The need for laboratory technicians}

Technicians in science have an essential role to play in current and future science education. They have considerable skill and expertise not available anywhere else. Trained and experienced technicians have a detailed knowledge of practical techniques and often greater expertise (than do the science teachers) in matters of technique, health \& safety, efficiency and economy. They also enable teachers to offer varied and stimulating science lessons. Recently, there has been much discussion about reducing the workloads of teachers by increasing the role of teacher assistants. Whilst technicians should not be used instead of teacher assistants, their support can help to make science teachers workloads more manageable. Inadequate levels of technician support can often be linked to underachieving science departments. The role of the science technician in UK secondary schools has, to date, been poorly considered by many schools as stated in Consortium of Local Education Authorities for the Provision of Science Services (CLEAPSS, 2009). This has impeded opportunities which could offer essential practical work support for science teachers (Soares \& Lock, 2007). Reasons are attributed to the lack of knowledge and understanding of how the technician's role, by school's senior management, is structured (Soares \& Lock, 2007).

Although expertise has been externally recognized, the technician's profile and professionalism has been underrated and unacknowledged by non-science school staff (Kind \& Taber, 2005). This poor regard, often by senior management, not only frustrates and offends technicians but also has prevented training and mutually beneficial progression of the role (Soares \& Lock, 2007). Technicians are not in schools to simply prepare solutions, wash glassware, clear away equipment and make the science teachers' coffee!

In most of African countries no laboratory technicians in schools in such situations teachers are forced to assume the role of technicians, as such laboratory practice and instruction is compromised due to time constraints in balancing between teaching and being a technician (Kapting'ei and Kimeli, 2014). Effective laboratory practice requires skills and professionalism that may not be achieved by untrained personnel as such instruction is compromised (Kapting'ei and Kimeli, 2014). But more than half of the technicians in schools were not trained in school's laboratory practice.

In all schools there is no facility except Awash and Aba'ala secondary schools in which there are some facilities but laboratories are not functional and equipments and chemicals are simply stored in non-ventilated store due to absence of skilled laboratory technicians and cooling system (Tolessa, 2016). In addition the survey research made in Ilu Ababora as one of hindering factors to practice laboratory experiments, which makes negative impact on students' academic achievement in science education was the absence of laboratory technician for Biology, Chemistry and Physics in the school, who can carefully practice in the laboratory (Feyera, 2014). Similarly, secondary schools of Bale Zone Southeast of Ethiopia most of the teachers (89\%) are not implementing due to the hindering factors called lack of laboratory technician (Abebe and et.al 2019a).

\subsection{Provision of Practical Session in School Timetable}

The basic frame work for learning special for practical work in science is availability of time. Following this the teachers and students needs enough time to carry out practical in science. Special practical work requires adequate time to teach and learn science. The problem of inappropriate time schedule becomes obvious when we realize that the last five minutes in each lesson periods are often expectedly devoted for entry behavior and closure of activities (Henshaw, 2013). To embrace the new perspective in science education system that is described as bookish and exist a gap between the school and the industries (Zuofa, 2007). We must devote adequate time for practical teaching instead of the lesson period to be one or two times 30-40 minutes each per week. If time for practical instruction is as important in learning as the designers of curriculum and many researchers think, the 
period for all practical in sciences must be increased to three or four periods of 40 minutes each per week.

Most of class time, that of the teacher's as well as of the students', is used for dealing with the practicalities of the tasks, that is giving instructions, collecting the equipment, handling them in producing the data and cleaning up afterwards (Abrahams, 2011). Very little or no time at all is devoted to discussing the ideas behind the phenomena or otherwise developing the conceptual skills of the students. In a prior study (Millar and Abrahams, 2009 ) found that most of the teachers in the study (24 out of 25) devoted very little or no time at all for supporting the development of the students' knowledge through discussion: the time was spent concentrating on the practicalities. They expected the correct deductions to arise from the results provided those were produced successfully. Due constraints emanating from other challenges e.g. inadequate laboratory equipment, single science laboratory or small laboratory space, time was wasted during shifts and in many cases practical activities wouldn't be as conclusive as required (Kapting'ei and Kimeli, 2014).

International comparisons (such as TIMSS) indicate that students in the UK spend more time on practical activities than do students in most other countries. Hence, a significant number of students in the UK see science experiments as being enjoyable. For example, an online survey of students $(n=1,450)$ reported that in terms of enjoyability of school science activities, the top three were 'going on a science trip or excursion' (85\%), 'looking at videos' (75\%) and 'doing a science experiment in class' (71\%) (Cerini et al. 2003, p.10). Teachers work load $69.81 \%$ of the teachers taught $16-20$ periods per week (Solomon \& et.al. 2015). $71.69 \%$ of the teachers taught five and more than five sections. Also $73.59 \%$ of the teachers taught 2 different grade levels. Hence, there must be adequate time that allotted for the implementation of practical work so that students can internalize what they have learnt.

\section{Exam and Assessment related issues}

Currently, there is little assessment of practical techniques such as assembling apparatus and measuring that require direct observation by the assessor, yet these skills are an essential part of practical work. We need to find better ways of assessing practical work to ensure that credit can be given for the acquisition of practical skill as well as scientific reasoning. A review of the science education assessment literature indicates that the compartmentalization of scientific learning continues to be a dominant perspective even today as measured by the contents of standardized tests used for international and national assessments in the United States. The research on assessment in science by Doran, Lawrenz and Helgeson (1994) shows that the traditional separation orientation is prominent. Their review of large scale international (IAE), national (NAEP) and state and provincial government assessments is a comprehensive listing of testing programs that rely on traditional distinctions and beliefs.

Many recent efforts remain strongly influenced by the tradition of laboratory practical examinations. For instance (Doran, Lawrenz \& Helgeson 1994) discussion of performance assessment focuses exclusively on laboratory and inquiry skills. For many science educators, laboratory practical examinations are alternative assessments. Hence, it is not surprising that the perspective of performance based assessments used in science today (Doran \& Tamir, 1992; Kanis, Doran \& Jacobson, 1990; Shavelson, Baxter, \& Pine, 1992) has a great deal in common with the practical examination formats promoted years ago (Hofstein \& Lunetta 1982; Lunetta \& Tamir, 1979; Lunetta, Hofstein \& Giddings, 1981; Tamir 1985). As one example, the report on alternative assessment of high school laboratory skills by Doran, Boorman, Chan and Hejaily (1993) partitions skills as they relate to planning, carrying out and analysing data from investigations as well as applying results to new contexts.

Many teachers lack experience with assessment methods aimed at assessing their students' understanding and performance in the science laboratory (Yung, 2001). As a result, in many cases, students' final grades do not include a component that directly reflects their performance in laboratory work and their understanding of that work. Furthermore, Brickhouse and Bodner (1992) reported that students' concerns about their grades have a strong influence on teachers' practices. More specifically, they suggested that some teachers will emphasize goals for learning and use teaching techniques that are aligned with students' ability to earn high grades. The second implication is that increased emphasis on the role of assessment in supporting instruction and educational reform forces greater attention to the consequences of assessment than has been usual. The validation of inferences is not only required about student achievement with respect to a defined domain and construct, but evidence is needed concerning the consequences of assessment practices for supporting instructional practices that lead to more successful learning for larger groups of students. This is, in assessment terminology, the consequential validity problem.

The most valid overall measure of attainment in any school subject must include a practical examination for practical work as an integral part of science (Alison, 1997). He went on further quoting that "the laboratory experiment or exercise refers to an instructional procedure in which cause and effect, nature or property of any object or phenomenon is determined by individual experience generally under controlled conditions". In other words, practical work should form the basis of teaching. Teachers did not involve assessment of the students, the overwhelming emphasis in the teachers' presentation of the task, and the discussion of students' actions and data, was on the substantive science content rather than on aspects of experimental design or the collection, analysis, 
and interpretation of evidence (Abrahams and Millar, 2008). The implicit assumption is that students will pick up a tacit understanding of what it means to plan and conduct an enquiry 'scientifically'. So their capability in science investigation can be tested at intervals, but does not have to be explicitly taught (Donnelly, 1996). This suggests that in England (and perhaps more widely) to develop models of practice in the use of practical work that more effectively integrate its roles in developing substantive and procedural understanding.

The Curriculum Assessment Policy Statement (CAPS) one of the major requirements of teachers should do at least one practical in physics per term, for the purpose of formal assessment (CAPS, 2012). The combined effect of the poor resources in schools and the CAPS requirement results in an observable lack of practical work in science classes. With the exception of the Advanced Higher Investigation units in the sciences, there is little formal recognition of practical work. The Standard Grade investigations and Learning Outcome tasks in current Higher and Intermediate courses can be reduced to hoops through which pupils are trained to jump by teachers keen to proceed apace with courses. There is hope that the new Curriculum for Excellence Highers has addressed this through Case Studies and Researching Units. Assessment in England and Wales has had a major impact on the amount and variety of practical work that many teachers carry out.

\section{Students related issues}

In our experience, both as teachers and observers of classroom practice, we have witnessed how excited learners often become when given the opportunity to do interesting hands-on science. Motivated learners in turn motivate teachers, who then provide more interesting kinds of practical work. One professional development strategy that has the potential to promote this upward spiral is to introduce innovative practices directly into the classroom. Instead of these practices being introduced to teachers in a venue that is removed from the classroom, they could be taught to learners with the teachers as participant observers. The Japanese practice of 'lesson study' does in fact take just this approach (Kita, Ndlalane, Nishioka, Ono \& Paulsen, 2007). Teachers, with or without outside support, plan jointly on how to introduce a particular innovation into a classroom. Finally, the lesson as practiced in the classroom is analyzed, and improvements suggested. If the learners are excited and challenged by jointly planned lesson, then all participating teachers are likely to become more motivated.

There is also evidence that students find practical work relatively useful and enjoyable as compared with other science teaching and learning activities. In survey responses of over 1,400 students of a range of ages (Cerini, Murray, \& Reiss, 2003), 71\% chose 'doing an experiment in class' as one of the three methods of teaching and learning science they found 'most enjoyable'. As reported in Solomon \& et.al. (2015) relatively large number of the students $377(48.45 \%)$ have moderate interest on physics. $66(8.48 \%)$ and $38(4.88 \%)$ had low and very law interest to learn physics, among these 362 (46.7\%), 312 (40.10\%) and $104(13.36 \%)$ lack interest due to subject difficulty, poor teaching method and plasma instruction respectively.

Students in the UK spend more time on practical activities than do students in most other countries. The evidence seems to suggest that the amount of practical work in schools science in the UK has not varied substantially in recent years. For example, in NESTA's survey of 510 UK science teachers, while $42 \%$ thought that the amount of practical work had increased over the preceding ten years, 32\% thought the opposite (NESTA, 2005). An online survey of students $(n=1,450)$ reported that in terms of enjoyability of school science activities, the top three were 'going on a science trip or excursion' $(85 \%)$, 'looking at videos' $(75 \%)$ and 'doing a science experiment in class' $(71 \%)$ (Cerini et al., 2003). But, when asked to choose the three methods that were most useful and effective in helping them to understand school science, $32 \%$ of respondents to an online survey chose 'doing a science investigation' and $38 \%$ chose 'doing a science experiment in classes.

However, some finding showed that the attitude of students towards practical science in secondary schools they were being scared by the measurements involved, lack of interest, annoyance during physics practical class and therefore do not prepare for it (Adedayo, 2015). It was also revealed from this study that even though the students' intelligent level can cope with physics practical activities, yet, prior negative impression about practical physics as being difficult, lack of interest in practical physics, considering practical physics as very tedious, too much of time spent during practical physics. The students were not interested to conduct practical activities, but the less admission and participation of students to science education result from assumption that less or absence of any practical activity in science subjects due to laboratory facilities have influence on their score in science and their future study (Negassa, 2014). Also in afar region survey made have identified of the total respondents $84.65 \%$ respond as they have interest of learning practical activity while $15.36 \%$ of them have no interest to it because of less practical activity implemented.

Students' interest and their academic achievement in science education have direct relation and as the same time affective practices of students in classroom are strongly related to their academic achievement (George \& Kaplan, 1998). Students are effectively successful through practicing the subject matters. Students tend to understand and recall what they see more than what they hear as a result of using laboratories in the teaching and learning of science students so as to get better achievement (Farounbi, 1998).

Therefore, motivated learners in turn motivate teachers, who then provide more interesting kinds of practical 
work. Students find practical work relatively useful and enjoyable as compared with other science teaching and learning activities. But, some students interest towards practical work in science at secondary schools they were being afraid by the measurements involved, lack of interest, annoyance during physics practical class and therefore do not prepare for it (Adedayo, 2015). The students were not interested to conduct practical activities, but the less admission and participation of students to science education result from assumption that less or absence of any practical activity in science subjects due to laboratory facilities have influence on their score in science and their future study. Students' interest and their academic achievement in science education have direct relation and as the same time affective practices of students in classroom are strongly related to their academic achievement.

\section{Curriculum related issues}

Many countries have given attention to the effective implementation and practice of science education at their secondary schools in their curriculum (Beyessa, 2014). The Natural Science section of the South African Revised Curriculum Statements of Curriculum 2005 (2005C) place a strong emphasis on 'doing science', as opposed to learning about the facts and theories of science. The relevant outcome, the first of three, is stated thus: "Learners act confidently on their curiosity about natural phenomena; they investigate relationships and solve problems in science, technology and environment contexts." (Department of Education, RSA, 2003). The document goes on to elaborate on this outcome by providing grade-specific standards in three major strands:- Planning investigations; Conducting investigations and collecting data; and Evaluating data and communicating findings. The production of quality professionals in science and technology is influenced by entrants who in turn influenced by the extent to which secondary education laid foundation in Mathematics and Natural Sciences as stated by Swail et al. (2003) cited in Hunde and Tegegne (2010). The implementation process of science education is limited in Ethiopian schools and students in Ethiopia generally perform poorly in science subjects (Samuel and Welflord, 2000).

\section{Educational administrations related issues}

School head is pivotal for the school to provide important facilities and laboratory room for the implementation and successful achievement of science educational quality. Some of the finding has indicated that reason for very little implementing practical activities were lack of concern and support of school principals (Endalamaw and et al., 2017). Adequate planning by the school head, with appropriate involvement of teachers, learners, parents and the community, can raise curriculum standards and help the school meet learning achievement goals and successfully implement their important policy directives or targets. The school head must be able to adjust the internal workings of the school to monitor and guide teachers' conditions of service and school financing system on implementation of practical work. Promote powerful learning-teaching processes that facilitate overall science educational achievement for all students. This occurs when school leadership sets realistic, but high expectations for both students and teachers, in the laboratory and classroom, and provides various ways for them to pursue learning through the active participation of the learner and the reflective guidance of the teacher. It would appear that in a school where innovation is generally supported, science teachers engage in higher levels of practical work (Hattingh, 2007).

Some studies have identified as School Management did not influence the implementation practical work in the school (Hattingh, 2007). It would appear that in a school where innovation is generally supported, science teachers engage in higher levels of practical work. A review in Ornstein and Hunkins (1998) examines that the school principals as key guarantor of successful implementation of the school curriculum so as to improve students' academic achievement. According to them, school principals are those who are knowledgeable and committed to the curriculum and they also view their roles in providing encouragements on one end of the continuum and serving as curriculum leaders on the other end.

Contrarily, studies indicated that he supports of school principals, is not in line with their duties and responsibilities stated in the policy (Feyera, 2014). Local school authorities have obligations and responsibilities towards schools in their municipalities. It is their duty to provide resources and funding for teachers and administrators, to provide quality learning materials for practical work and to monitor school planning and progress. Both local and national education authorities monitor the performance of specific schools. The local education authorities are responsible for supervision of teachers, school managers and for the allocation of learning spaces, equipment and instruments for the implementation of practical work. They are accountable to the community for resource allocation. In decentralized government systems, community members, parents and children have greater opportunities to participate in planning, implementing, monitoring and evaluating child friendly science practical activities and governance.

In the decentralized education structure of Ethiopia, Woreda Education Offices (WEOs) has been given mandated to give vital support for the implementation of teachers' programs. Thus, they have roles and responsibilities (MOE, 2004) to: plan, organize, coordinate, supervise and support and ensure their effective implementation of science education in the local context, so as to enhance students' performance. In addition to this, the contribution of Non-Governmental Organizations (NGOs) to the improvement of science education should 
not be under estimated as stated by Strengthening Mathematics and Science Education in Ethiopia (SMASEE 2012). It is obvious that schools have to provide by necessary materials (books, classrooms, laboratory materials, guidance on teaching learning of science education and others) for students so that students have to get access in achieving their science subjects effectively (Norhidayah Ali, et.al., 2009). Generally, some educational experts argue that students' poor attendance made by schools is not only hinders academic achievement but also promotes a poorly educated society and thus leads to many negative social issues. That is, poor attendance, proceeds to low achievement, increases the dropout rate, and amplifies a host of social problems.

The Commission for Africa report recommends that African countries have to take specific action that strengthen science, engineering and technology capacity since such knowledge and skills help countries to find their own solution to their own problem (Teshome, 2007). Similarly, currently the Ethiopian government determined and introduced what is now known as a "70:30 professional mix which $70 \%$ will be Science and technology streams while $30 \%$ will be Social Sciences and Humanities streams at higher education. This demonstrated that the government has given due consideration to science education (Tesfaye et al., 2010). Therefore, the attention given by higher authorities for schools can affect directly or indirectly the implementation practical work in science education.

\section{Conclusion}

Practical work in science teaching and learning situations that offer learners opportunities to practice the process of investigations. It is also practical work would involve hands-on and minds-on practical learning opportunities where learners practice and develop various process skills including hypothesizing, observation, interpreting, predicting, problem solving, communicating, and drawing and evaluating conclusions.

The role of practical work in science teaching recorded in the literature includes encouraging accurate observation and description, making phenomenon more real, arousing and maintaining interest and promoting a logical and reasoning method of thought. It is also understanding of how science works: concepts of scientific process, collaborative working, reproducible results, fair testing. In Science, learners do practical work to expand their knowledge in an attempt to understand the world around them. Achievement and skills improved when students are taught science using practical work.

The implementation and attention given to practical work at secondary school found at different levels in different countries. Countries like United Kingdom, Germany, Hong Kong and Thailand has a very strong emphasis on practical work unlike the majority of other countries like Greece, Spanish, Ireland and African countries like Ethiopia, Kenya South Africa. Teachers rarely conduct practical work, mainly due to the scarcity of resources.

The main factors frequently indicated for the failure of implementation include: Large class size and lack of resources, lack of laboratories and lab equipment; lack of laboratory technicians; and large classes. The others factors are related to absence of laboratory technicians, teacher's perception and motivation, teachers' skills competence, teachers work experience, teachers work load and job satisfaction, class time allotted are determinates identified for practical work implementation. Exam and assessment related issues, students' related issues, curriculum related issues and educational administrations related issues are also factors for practical work implementation.

Consequently, in the absence or poor implementation of practical work learners' performance in science subjects would be poor and lose interest. The other finding that has important implications is that the doing of practical work is significantly dependent on teachers' motivation. Those who are motivated to do practical work will find ways to do so even in the most poorly resourced of schools. Conversely those who are not motivated will not do practical work even when they have access to the best of resources. Many schools in Ethiopia have large class sizes with few possibilities of meaningful group or individual work and few opportunities for direct contact with teachers and to implement practical work.

In most of African countries no laboratory technicians in schools: at the time of the study some school had no laboratory technicians. In such situations teachers are forced to assume the role of technicians, as such laboratory practice and instruction is compromised due to time constraints in balancing between teaching and being a technician. Time for practical instruction is as important in learning as the designers of curriculum and many researchers think, the period for all practical in sciences must be increased to three or four periods of 40 minutes each per week. But in most countries there is not time allotted as one of the schedule to implement practical work special in African countries like Ethiopia. Practical works in secondary schools of Ethiopia are also subject to the identified factors hindering its proper implementation. It was indicated that secondary students do not receive the practical experiences specified in the official science curriculum. Hence, basic determinant factors for the practical work implementation and practice in science education at secondary schools have been identified.

Many countries have given attention to the effective implementation and practice of science education at their secondary schools in their curriculum. But the implementation process of practical work in science education is still limited in Ethiopian schools and students perform poorly in science subjects. To improve the use of laboratory 
method in the quality of science education; Government and others non-government donors should provide Physical resources. The curriculum developments that will enhance the use of laboratory method and improve the quality of science instruction in schools have to be evaluated and developed timely. Also researchers must participate in conducting sound research to identify challenges of particular areas of secondary schools facing in implementing practical work Ethiopia.

\section{References}

1. Abebe A., Ibrahim K., Shiferaw W., Esayes A. \& Tekalign K. (2019a). Effect Analysis on Laboratory Work Skill Training Provided by Madda Walabu University for Secondary Schools (2013-2017G.C) in Bale Zone, South East Ethiopia. Journal of Education and Practice, 10(13): 71-77.

2. Abebe A., Ibrahim K., Shiferaw W., Esayes A. \& Tekalign K. (2019b). Determinant Factors Affect the Implementation of Laboratory Work in Science Subjects at Secondary Schools in Bale Zone, Ethiopia. Journal of Education and Practice, 10(13): 78-85.

3. Abimbola, I.O. (1996). Advances in the assessing students' science knowedge. Paper development and validation of instruments for presented at the National Conference on Educational Assessment held at the Lagos Airport Hotel, Ikeja, Lagos, 9-13.

4. Abrahams, I. \& Millar, R., (2008) Does Practical Work Really Work? A study of the effectiveness of practical work as a teaching and learning method in school science, International Journal of Science Education, 30:14, 1945-1969, International Journal of Science Education, 30 (14): 1945-1969.

5. Adedayo, J. (2015). Analysis of factors influencing students' attitudes towards practical aspect of secondary school physics in Ekiti state. International Journal of Multidisciplinary Research and Development. 2: 417-421

6. Adugna Mosissa, (2017). Efficiency of Practical-Based Education in Preparatory Schools, the Case of Horo Guduru Wollega Zone, Ethiopia. Science publishing group 3(3): 14-22

7. Ajayi, P. (2008). Evaluation of the implementation of senior secondary school physics practical activities in Nigeria. Research in Curriculum Studies. 5: 90-99.

8. Aladejana, F. \& Aderibigbe O. (2007). Science Laboratory Environment and Academic Performance Journal of Science Education and Technology, 16 (6): 500-506

9. Alsop, T. (1991). Practical science in low-income countries. In B. E. Woolnough (Ed.), Practical science Open University Press, Milton Keynes, 31-40.

10. Baker, D. \& Smith, T. (1997). Teacher turnover and teacher quality: Refocusing the issue, Trend 2. Teachers College Record, 99(1): 29-35.

11. Bello A., (2008) Improving the teaching of chemistry practical Effective methods of teaching chemistry practical. Chemistry panel senses. A Handbook for chemistry teachers STAN.

12. Benner, S. (2011). What Scientists do The BIOLOGOS From http://biologus.org Accessed 26 May 2014.

13. Beyessa, F. (2014). Major Factors that Affect Grade 10 Students' Academic Achievement in Science Education at Ilu Ababora General Secondary of Oromia Regional State, Ethiopia. International Letters of Social and Humanistic Sciences. 32: 118-134.

14. Brickhouse, N., \& Bodner, G. M. (1992). The beginning science teacher: Classroom narratives of convictions and constraints. Journal of Research in Science Teaching, 29: 471-485.

15. Cerini, B., Murray, I., \& Reiss, M. (2003). Student review of the science curriculum. Major findings. London: Planet Science/Institute of Education University of London/Science Museum. Retrieved February 27, 2007, from http://www.planet science.com/sciteach/review.

16. Consortium of Local Education Authorities for the Provision of Science Services, (2009), DL228, Technicians and Their Jobs, Uxbridge.

17. Curriculum Assessment Policy Statement (2012). Department of Basic Education Government of South Africa.

18. Darling-Hammond, L. (2003). Keeping Good Teachers: Why it matters. What leaders can do. Educational Leadership, 60 (8): 6-13.

19. Department of Basic Education (2012a). National Senior Certificate Examination. Portfolio Committee on Basic Education, (online).

20. Department of Education, RSA (2003). Revised National Curriculum Statements Grades R-9: Natural Sciences. Pretoria: Government printer.

21. Donnelly, J. (1996). Curriculum development in science: The lessons of Sc1. School Science Review, 76 (277): 95-103.

22. Donnelly, J., Buchan, A., Jenkins, E., Laws, P., \& Welford, G. (1996). Investigations by order. Policy, curriculum and science teachers' work under the Education Reform Act. Nafferton, UK: Studies in Education Ltd.

23. Doran, R. \& Tamir, P. (1992) ‘An International Assessment of Science Practical Skills', Studies in Educational Evaluation, 18: 263-406

24. Doran, R., Boorman, J., Chan, F. \& Hejaily, N.: (1993). 'Alternative Assessment of High School Laboratory 
Skills', Journal of Research in Science Teaching, 30: 1121-1131

25. Doran, R., Lawrenz, F. \& Helgeson, S. (1994). 'Research on Assessment in Science', in D. Gabel (ed.), Handbook of Research on Science Teaching and Learning, Macmillan, NY, 388-44

26. Endalamaw, D., Abebe, A., Meareg, G., (2017). An Investigation in to the Combined and Relative Influences of Some Selected Factors on Students' Performance in Physics. Journal of Education and Practice, 8(19): 5259.

27. Farounbi, M. (1998). Resource concentration, utilization and management correlates of students'. Learning outcomes: a study in school quality in Oyo State. University of Ibadan, Ibadan.

28. Farzana, D., (2014). Biology Teachers' Perception of Laboratory Work in Afghanistan. Karlstads University.

29. Feyera, B. (2014). Major Factors that Affect Grade 10 Students' Academic Achievement in Science Education at Ilu Ababora General Secondary of Oromia Regional State, Ethiopia International Letters of Social and Humanistic Science. 32: 118-134

30. FSS (Forum for Social Study), (2002E.C). A.A

31. Gebrekidan, T., Annette, L., and Kvittingen, L., (2014). Small-Scale Chemistry For A Hands-On Approach To Chemistry Practical Work In Secondary Schools: Experiences From Ethiopia. AJCE. 4(3):48-94

32. George R., Kaplan M. D. (1998). A structural model of parent and Teacher influences on students' attitudes of eight grades. Evidence from NELS. 88 Science, 82(1): 93-109.

33. Goddard R. D. (2003). Relational networks, social trust, and norms: A social capital perspective on students' chances of academic success. Educational Evaluations \& Policy Analysis, 25;:59-74.

34. Gray, B.V. (1999). Science Education in the Developing World: Issues and Considerations. Journal of Research in Science Teaching, 36 (3): $261-268$.

35. Hattingh, A., (2007). Some factors influencing the quality of practical work in science classrooms. African Journal of Research in SMT Education, 11(1): 75-90.

36. Helliar, A.T. \& Harrison, T.G. (2011). The role of school technicians in promoting science through practical work. Acta Didactica Napocensia, 4(2- 3): 2011.

37. Henshaw .H. N. (2013). Chemistry Education, a tool for social Reconstruction and Transformation in Nigeria Problems and Prospects. Niger Delta Journal of Education, 2, 171-178.

38. Hodson, D. (1993). Practical work in science: Time for a reappraisal. Studies in Science Education, 19, 175184.

39. Hofstein, A. \& Lunetta, V. (1982). 'The Role of the Laboratory in Science Teaching: Neglected Aspects of Research', Review of Educational Research 52: 201-217

40. Hofstein, A. (2004). "The laboratory in chemistry education: thirty years of experience with developments, implementation and evaluation". Chemistry Education Research and Practice. 5:247-264.

41. Hofstein, A., Lunetta, V.N. (2003). The Laboratory in Science Education: Foundations for the TwentyFirst Century. Science Education. The Pennsylvania State University, University Park.

42. Hofstein, A., Lunetta, V.N. (2004). "The laboratory in science education: foundation for the $21^{\text {st }}$ century". Science Education. 88:28-54

43. House of Commons. (2002a,). Select Committee on Science and Technology Third Report. House of Commons Parliament:

44. Hunde, A. B., Tegegne, K. M. (2010). Qualitative Exploration on the Application of Student centered Learning in Mathematics and Natural Sciences: The case of Selected General Secondary Schools in Jimma, Ethiopia. Ethiop. J. Educ. \& Sc., 6 (1).

45. Kanis, I., Doran, R. \& Jacobson, W. (1990), Assessing Science Process Laboratory Skills at the Elementary and Middle/Junior High Levels, National Science Teachers' Association, Washington, DC.

46. Kapting'ei, P. and Kimeli, D. (2014). Challenges Facing Laboratory Practical Approach In Physics Instruction In Kenyan District Secondary Schools. International Journal Of Advancements In Research \& Technology. 3:, 2278-7763.

47. Kerr, J. F. (1963). Practical work in school science: an account of an inquiry sponsored by the Gulbenkian Foundation into the nature and purpose of practical work in school science teaching in England and Wales (2nd ed.). Leicester: Leicester University Press.

48. Kibirige, I., Maake, M. and Mavhunga, F.,(2014). Effect of Practical Work on Grade 10 Learners' Performance in Science in Mankweng Circuit, South Africa. Mediterranean Journal of Social Sciences, 5, 23.

49. Kibirige, I., \& Tsamago, H. (2013). Learners' Performance in Physical Sciences Using Laboratory Investigations. International Journal of Educational Sciences, 5(4): 425-432.

50. Kibirige, I., Osodo, J. \& Tlala, K.M. (2014). The effect of Predict-Observe- Explain Sttrategy on Learners' Misconceptions about Dissolved Salts. Mediterranean Journal of Social Sciences, 5(4):300-310.

51. Kind V. \& Taber, K., (2005). Science: teaching school subjects 11-19, Routledge, London.

52. Kolucki, B. \& Lemish, D. (2011). Communicating with Children Principles and Practices to Nurture, Inspire, Excite, Educate and Heal. UNICEF. 
53. Leach, J., \& Paulsen, A. C., (1999). Practical work in science education: recent research studies. Denmark: Roskilde University Press.

54. Lunetta, V N, Hofstein, A and Clough, M., (2007). Teaching and learning in the school science laboratory. An analysis of research, theory, and practice. In Handbook of research on science education (ed. S K Abell and N G Lederman), Mahwah, NJ: Lawrence Erlbaum Associates.393-431.

55. Lunetta, V.N., \& Tamir, P. (1979). Matching lab activities with teaching goals. The Science Teacher, 46(5): 22-24.

56. Makgato, M. (2007). Factors associated with poor performance of learners in Mathematics and Physical Science in Soshanguve, South Africa, Africa Education Review, 4 (1,): 89 -103.

57. Martínez-Losada, C., \& García-Barros, S. (2005). Do Spanish secondary school teachers really value different sorts of procedural skills? International Journal of Science Education, 27 (7) : 827-854.

58. Marzano, R. J. (2003). Classroom management that works research-based strategies for every teacher. Alexandria, VA: Association for Supervision and Curriculum Development.

59. Millar, R. (2004). The role of practical work in the teaching and learning of science. National Academy of Sciences, Washington, DC.

60. Mji, A., \& Makgato, M. (2006). Factors associated with high school learners' poor performance: a spotlight on mathematics and physical science. South African Journal of Education, 26(2):253-266.

61. MoE (2002). Educational Organization and, Community Participation and Financial Guideline: Addis Abeba EMPDA, August.

62. Mokotedi, R.T. (2013). Beginning Primary School Teachers' Perspectives on the Role of Subject Specialization in Botswana Colleges of Education. International Journal of Scientific Research in Education 6(1): 88-99.

63. Muwanga-Zake, J.W.F. (2008). Is Science Education in a Crisis? Some of the Problems in South Africa. Science in Africa. www.scienceinafrica.co.za / scicrisis.htm Accessed: 28 May 2014.

64. National Endowment for Science, Technology and the Arts (NESTA) (2005a). Science Teachers Survey. London: NESTA. Available ht: ht//www.planet science.com/sciteach/realscience/science_teachers_report.pdf (accessed on February 18, 2008).

65. Negassa, O. (2014). Ethiopian Students' Āchievement Challenges in Science Education: Implications to Policy Formulation. AJCE, 4(1).

66. Norhidayah Ali Kamaruzaman, Jusoff Syukriah Ali Najah, Salamt Mokhtar Azni Syafena Andin (2009). 'The Factors Influencing Students' Performance at Universiti Teknologi MARA Kedah, Malaysia'. Canadian Research \& Development Center of Sciences and Cultures, 3(4).

67. Ogunleye (2001). prioritizes the lack of adequate qualified and experienced physics teachers and of laboratory equipment as two major recurring problems of teaching physics in secondary schools.

68. Oni, J.O., (1995). Educational Resource: An Introduction; Abeokuta, Gbemi Sodipo Press Ltd.

69. Onwu, G., Stoffel, N. (2005). Instructional functions in large, under-resourced science classes: Perspectives of South African teachers. Perspectives in Education, 23(3): 65-75.

70. Ostroff, C. (1992). The relationship between satisfaction, attitudes, and performance: An organizational Level Analysis. Journal of Applied Psychology, 77: 963-974.

71. Oyoo, S. O. (2013). Enhancing and Sustaining Teacher Effectiveness as the 'Trojan Horse' in successful Science Education in Kenya; In C.J. Craig, P.C. Meijer and J. Broeckmans (Eds), From Teacher Thinking to Teachers and Teaching: The Evolution of a Research Community, Advances in Research on Teaching. Bingley, UK: 19: 457-477.

72. Ramnarain, U. (2010). Teaching scientific investigations. Northlands, SA, Macmillan.

73. Ramnarain, U. (2014). Teachers' perceptions of inquiry-based learning in urban, suburban, township and rural high schools: The context specificity of science curriculum implementation in South Africa. Teaching and Teacher Education, 38: 65-75.

74. Science Community Representing Education, SCORE. (2008). Practical work in science: a report and proposal for a strategic framework. London: Science Community Representing Education (SCORE). Science Review, $91(335):$, 49-51.

75. Séré, M.-G. M.-G. (2002). Towards renewed research questions from the outcomes of the European project Labwork in Science Education. Science Education, 86(5),

76. Shavelson, R., Baxter, G. \& Pine, J. (1992). 'Performance Assessments: Political Rhetoric and Measurement Reality', Educational Researcher 21: 22--27.

77. SMASEE (2012). Introducing Strengthening Mathematics and Science Education in Ethiopia (SMASEE) and monitoring and evaluation. Addis Ababa.

78. Smithers, A. \& Robinson, P. (2005). Physics in schools and colleges: teacher deployment and student outcomes. Buckingham, UK: Carmichael Press, University of Buckingham.

79. Soares, A. \& Lock, R. (2007). Pre-Service Science Teachers' Perceptions of Written Lesson Appraisals: The Impact of Styles of Mentoring. European Journal of Teacher Education, 30(1): 75-90.A 
80. Solomon, G. \& Kedir, O., (2015). Problems in the Teaching and Learning of Physics at the Secondary and Preparatory Schools, the Cases Wolaita and Dwuro Zones. Global Journal of HUMAN-SOCIAL SCIENCE: G Linguistics \& Education, 15.

81. Solomon, J. (1994). Science education from a European perspective. In M. Ratcliffe (Ed.), ASE guide to secondary science education. Stanley Thornes: Cheltenham, 52-56.

82. Solomon, J. (1998). The laboratory comes of age. In R. Levinson. (Ed.). Teaching Science London: Routledge, 7-21.

83. Tamir, P. (1977). How are Laboratories Used? Journal of research in science teaching, 14(4) Retrieved 201408-05 fromhttp://onlinelibrary.wiley.com/

84. Tenaw, Y, A. (2015). Effective strategies for teaching chemistry. International Journal of Education Research and Reviews, 3 (3): 078-084.

85. Tesfamariam, G., Lykknes, A., Kvittingen, L. (2014). Small-scale Chemistry for a Hands-on Approach to Chemistry Practical Work in Secondary Schools: Experiences from Ethiopia. AJCE, 4(3), Special Issue (Part II).

86. Tesfaye, T., Yitbarek, S. Tesfaye, A. (2010). Status of Science Education in Primary Schools of Addis Ababa. City Government of Addis Ababa Education Bureau.

87. Tolessa, M. And Mohammed, S., (2016). Factors Affecting Implementation Of Practical Activities In Science Education In Some Selected Secondary And Preparatory Schools Of Afar Region. Ajce, 6(2)

88. Tsai, C. (2003). Taiwanese science students' and teachers' perceptions of laboratory learning environment: exploring epistemological gaps. International Journal of Science Education,25(7) :847-860.

89. Turpin, T. \& Cage, B.N. (2004). The effects of an integrated, activity-based science curriculum on student achievement, science process skills, and science attitudes. Electronic Journal of Literacy through Science, 3:117.

90. Watts, A. (2013). The assessment of practical science: a literature review. Cambridge Assessment.

91. Wellington, J. (2005). Practical work and the affective domain: of Science and technology education library. The Netherlands: Springer. 29:99-110

92. Woodley, E. (2009). Practical work in school science: why is it important? School Science Review, 91 (335) :49-51.

93. Woolnough, B. E. (1998). Authentic science in schools, to develop personal knowledge. In J. Wellington (Ed.), Practical work in school science: Which way now? (pp. 109-125). London: Routledge

94. Yung, B. H. W. (2001). Three views of fairness in a school-based assessment scheme of practical work in biology. International Journal of Science Education, 23: 985-1005.

95. Zuofa .K. (2007). Refocusing Education for relevance and sustainable National Development. Journal of knowledge review 15(1):14-24. 